Gut and Liver, Vol. 11, No. 4, July 2017, pp. 512-519

\title{
Association of Inflammatory Bowel Disease (IBD) with Depressive Symptoms in the United States Population and Independent Predictors of Depressive Symptoms in an IBD Population: A NHANES Study
}

\author{
Sanjay Bhandari ${ }^{1}$, Michael E. Larson ${ }^{1}$, Nilay Kumar ${ }^{2}$, and Daniel Stein ${ }^{3}$ \\ ${ }^{1}$ Department of Medicine, Medical College of Wisconsin, ${ }^{2}$ Division of Gastroenterology and Hepatology, Aurora St. Luke's Medical Center, and \\ ${ }^{3}$ Division of Gastroenterology and Hepatology, Medical College of Wisconsin, Milwaukee, WI, USA
}

See editorial on page 449 .

Background/Aims: There is a paucity of population-based studies on the association between inflammatory bowel disease (IBD) and depression in the U.S. population. We sought to study this association using the National Health and Nutrition Examination Survey (NHANES) database. Methods: We used NHANES data from 2009 to 2010. Our study included 190,269,933 U.S. adults without IBD and 2,325,226 with IBD. We sought to determine whether IBD is an independent risk factor for depressive symptoms (DS) in the U.S. population and studied the independent predictors of DS in IBD population. Results: DS was present in 49\% of the IBD population versus $23 \%$ of the non-IBD population $(p<0.001)$. During the multivariate analysis, we found that IBD was independently associated with DS in the U.S. population ( $p=0.002)$. The independent predictors of DS in the IBD population were older age $(p=0.048)$ and divorced/separated/widowed status $(p=0.005)$. There was nonsignificant increase in suicidal risk in IBD population with DS versus that in non-IBD population with DS ( $27 \%$ vs $12 \%$, respectively, $p=0.080$ ). Only $36 \%$ of IBD individuals with DS visited mental health professional or psychiatrist within the past year. Conclusions: IBD is independently associated with DS in the U.S. population. Further research is warranted on risk stratification, screening and management of those with IBD who are at risk of depression. (Gut Liver 2017;11:512-519)

Key Words: Inflammatory bowel disease; Depressive; United States; Population; National survey

\section{INTRODUCTION}

It is estimated that over one million people live with inflammatory bowel disease (IBD) in the United States. This is split between ulcerative colitis (UC) and Crohn's disease (CD), with UC being slightly more prevalent. ${ }^{1,2}$ IBD is an incurable disease with a relapsing and remitting course which has serious implications for patients from a physical and psychological perspective. Patients with IBD experience significant morbidity including lower health-related quality of life, lost earnings, and increased medical expenses. ${ }^{3}$ Given the chronic nature of the disease, current research and treatment strategies focus on reducing active disease and disease flares. ${ }^{4}$

Ongoing research in IBD focuses on the prevalence of comorbid depression and how this coinciding diagnoses effects patient outcomes. Multiple prospective studies have shown that psychological factors including depressive mood, anxiety, and stress contribute to increased numbers of IBD flares which portend worse disease outcome and health care related quality of life in IBD patients. ${ }^{5-7}$ Depression in the setting of IBD is also associated with decreased adherence to treatment regimens ${ }^{8}$ as well as decreasing short and long term efficacy of infliximab treatment. ${ }^{9}$ Given that depression worsens outcomes for IBD patients, it is helpful to understand the prevalence of depression in IBD patients. Population based studies show a significantly higher rate of depression in IBD patients, ${ }^{10}$ especially in the first year before or after diagnosis. ${ }^{11}$ Therefore, an understanding of the risk factors for depression in patients with IBD can potentially help to accurately identify those most at risk for poor disease outcomes related to depression. This study aims to utilize National Health and Nutrition Examination Survey (NHANES) data to further understand depression relating to IBD from a

Correspondence to: Sanjay Bhandari

Department of Medicine, Medical College of Wisconsin, 9200 W Wisconsin Ave, 5th Floor, Clinical Cancer Center, Milwaukee, WI 53226, USA

Tel: +1-414-805-0820, Fax: +1-414-805-0988, E-mail: sbhandari@mcw.edu

Received on July 13, 2016. Revised on October 4, 2016. Accepted on November 2, 2016. Published online April 11, 2017

pISSN 1976-2283 eISSN 2005-1212 https://doi.org/10.5009/gnl16347

@ This is an Open Access article distributed under the terms of the Creative Commons Attribution Non-Commercial License (http://creativecommons.org/licenses/by-nc/4.0) which permits unrestricted non-commercial use, distribution, and reproduction in any medium, provided the original work is properly cited. 
North American population perspective.

\section{MATERIALS AND METHODS}

\section{Data source}

We used data from NHANES which is a cross-sectional survey of a nationally representative sample of the civilian, noninstitutionalized U.S. population. ${ }^{12}$ NHANES is conducted by the National Center for Health Statistics (NCHS), Centers for Disease Control and Prevention. The survey performs medical interviews, physical examinations and laboratory testing on a nationally representative sample of U.S. citizens. We used NHANES data from year 2009 to 2010 when all adults of 20 to 69 years old were asked whether they had IBD. In addition to demographics, participants were asked on depressive symptoms (DS) ("Over the last 2 weeks, how often have you been bothered by the following problems: feeling down, depressed or hopeless?") and suicidal thoughts ("Over the last 2 weeks, how often have you been bothered by the following problems: thoughts that you would be better off dead or hurting yourself in some way?"). We first compared IBD and non-IBD population and sought to see if IBD is an independent risk factor for DS in U.S. population. Then we tried to elicit the independent predictors of DS in IBD population.

\section{Statistical analysis}

All categorical variables are presented as weighted percentages. Chi-square test was performed to analyze categorical variables. Continuous variable like C-reactive protein was presented as mean with standard error. Student t-test was performed for the analysis for the continuous variable. The multivariate logistic regression model was used which incorporated all covariates with $\mathrm{p}<0.2$ on univariate analysis. In order to account for the survey's complex design, our analysis incorporated sampling weights (WTMEC2YR), as well as the stratum variable (SDMVSTRA) and the cluster variable to specify primary sampling unit (SDMVPSU). All calculations were two-tailed and $\mathrm{p} \leq 0.05$ was considered significant. All analyses were performed using survey procedures in SAS 9.4 (SAS Institute, Cary, NC, USA). NHANES 2009 to 2010 was approved by NCHS Research Ethics Review Board with continuation of Institutional Review Board Protocol \#2005-06 and can be accessed online (http://www.cdc. gov/nchs/tutorials/nhanes/surveyorientation/Navigate/Frame7. htm).

\section{RESULTS}

\section{Baseline characteristics of IBD and non-IBD population}

Our study included 190,269,933 U.S. adults without IBD and 2,325,226 with IBD. IBD and non-IBD population differed from each other in age-category and racial distribution (Table 1). Further, adults with IBD adults were likely to be overweight and have more comorbidities than those with non-IBD (Table 1). Nine percent of IBD population and 11\% of non-IBD did not respond questions on DS. DS was present in 49\% of those with IBD versus 23\% in those without IBD (unadjusted odds ratio [OR], $3.1 ; 95 \%$ confidence interval [CI], 1.6 to $6.1 ; \mathrm{p}<0.001$ ).

\section{Independent risk factors associated with DS in U.S. population}

On multivariate analysis that included all the variables with p-values $<0.2$ from the univariate analysis, IBD was independently associated with DS (adjusted OR, 3.1; 95\% CI, 1.6 to 5.9; $\mathrm{p}=0.002$ ) (Table 2). In addition to IBD, other factors associated with DS in U.S. population were higher number of comorbidities. Those with 2 and $\geq 3$ comorbidities had higher risks of DS with ORs of 1.6 (95\% CI, 1.2 to 2.2; p=0.004) and 2.4 (95\% CI, 1.8 to $3.2 ; \mathrm{p}<0.001)$ as compared with those with no comorbidities, respectively. The factors which were protective of DS were older age (>50 yr vs $20-50$ yr: OR, 0.7; 95\% CI, 0.6 to $0.8 ; \mathrm{p}<0.001$ ) and educational level of college degree or higher (OR, 0.7; 95\% CI, 0.5 to $0.9 ; p=0.021)$ and higher income poverty ratio $(\geq 500 \%$ vs < 100\%: OR, 0.5; 95\% CI, 0.4 to 0.7; p<0.001 and 300\%$499 \%$ vs <100\%: OR, 0.6; 95\% CI, 0.4 to $0.8 ; \mathrm{p}=0.001$ ) (Table 2).

\section{Factors associated with DS in IBD population}

On univariate analysis, factors associated with DS in IBD population were marriage status (more in divorced/separated/ widowed), anemia and IBD types (more in UC vs CD) (Table 3). On multivariate analysis that included all the variables with $\mathrm{p}$ values $<0.2$ from the univariate analysis, the factors associated with DS in IBD population were older age (>50 yr vs 20-50 yr: OR, 3.13; 95\% CI, 1.01 to $9.70 ; \mathrm{p}=0.048$ ) and divorced/separated/widowed (vs married/living with partner: OR, 32.8; 95\% CI, 3.9 to 277.9; $\mathrm{p}=0.005$ ) (Table 4).

\section{Visit to mental health professional/psychiatrist and risk of suicide}

Among those who had DS, 36\% of IBD versus 15\% of nonIBD patients visited mental health professional or psychiatrist in the past 1 year $(p=0.02)$. There was trend toward increased suicidal ideation in IBD with DS versus non-IBD population with DS (27\% vs $12 \%, \mathrm{p}=0.08$ ). Among those who had suicidal ideation, $86 \%$ of IBD versus 23\% of non-IBD individuals visited the mental health professional or psychiatrist in the past year $(\mathrm{p}<0.001)$ (data not shown).

\section{DISCUSSION}

This study utilized NHANES data with the goal of better understanding the prevalence of DS and associated risk factors of DS in patients with IBD from a U.S. population perspective. Results show that IBD is independently associated with higher prevalence of DS in our projected U.S. population based study. 
Table 1. Comparison between the Non-IBD and IBD Populations

\begin{tabular}{|c|c|c|c|}
\hline Covariate & $\begin{array}{c}\text { Non-IBD } \\
(n=190,269,933)^{*}\end{array}$ & $\begin{array}{c}\text { IBD } \\
(n=2,325,226)^{*}\end{array}$ & p-value \\
\hline Age, yr & & & 0.031 \\
\hline $20-50$ & 67 & 50 & \\
\hline$>50$ & 33 & 50 & \\
\hline Male sex & 49 & 42 & 0.401 \\
\hline Race & & & 0.041 \\
\hline Non-Hispanic White & 66 & 81 & \\
\hline Non-Hispanic Black & 12 & 6 & \\
\hline Others $^{\dagger}$ & 22 & 13 & \\
\hline Education & & & 0.132 \\
\hline$<$ High school & 18 & 21 & \\
\hline High school & 23 & 7 & \\
\hline Some college & 31 & 40 & \\
\hline$\geq$ College & 29 & 32 & \\
\hline Married & & & 0.201 \\
\hline Married/living with partner & 69 & 56 & \\
\hline Divorced/separated/widowed & 17 & 25 & \\
\hline Never married & 14 & 19 & \\
\hline Income poverty ratio & & & 0.134 \\
\hline$<100$ & 22 & 16 & \\
\hline $100-299$ & 31 & 35 & \\
\hline $300-499$ & 22 & 11 & \\
\hline$\geq 500$ & 25 & 38 & \\
\hline Smoking ${ }^{\ddagger}$ & 44 & 51 & 0.501 \\
\hline Overweight ${ }^{\S}$ & 33 & 57 & $<0.001$ \\
\hline Anemia" & 3 & 5 & 0.643 \\
\hline C-reactive protein, $\mathrm{ng} / \mathrm{mL}$ & $0.37 \pm 0.02$ & $0.46 \pm 0.16$ & 0.543 \\
\hline No. of comorbidities ${ }^{\pi}$ & & & $<0.001$ \\
\hline 0 & 58 & 29 & \\
\hline 1 & 27 & 44 & \\
\hline 2 & 10 & 21 & \\
\hline$\geq 3$ & 5 & 6 & \\
\hline
\end{tabular}

Data are presented percent or mean \pm standard error.

IBD, inflammatory bowel disease.

*The data are presented as numbers that have been weighted for a national estimate; ${ }^{\dagger}$ Others include Mexican American, other Hispanics and oth-

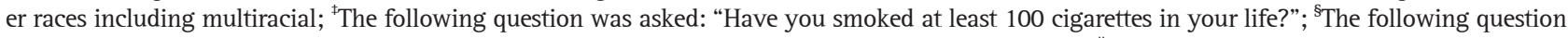
was asked: "Has a doctor or other health care professional ever told you that you were overweight?"; "The following question was asked: "During the past 3 months, have you been on treatment for anemia, sometimes called "tired blood" or "low blood"? (include diet, iron pills, iron shots, transfusions as treatment)"; "Comorbidities included hypertension, diabetes, coronary artery disease, stroke, congestive heart failure, liver disease, kidney disease, asthma, and cancer. All comorbidities were self-reported.

Additionally, the significant risk factors for DS in the IBD patient population differed from the general population. These differing risk factors include older age and marital status (divorced/ separated/widowed). This potentially imply the psychological stress associated with increasing age and lack of family support given the burden in IBD care. Our study also found that there was nonsignificant increase in suicidal risk in IBD population with DS than that in non-IBD population with DS, which might imply the increased urgency of healthcare need in depressed IBD population. Our data also shows that only 36\% of IBD population with DS currently seek mental health care, highlighting on the possible underutilization of mental health care in depressed IBD population.

Previous research clearly outlines higher rates of major de- 
Table 2. Independent Factors Associated with Depressive Symptoms in the U.S. Population

\begin{tabular}{|c|c|c|c|c|}
\hline Independent predictor* & $\mathrm{OR}$ & Lower limit of 95\% CI & Upper limit of 95\% CI & $\mathrm{p}$-value \\
\hline \multicolumn{5}{|l|}{ IBD } \\
\hline Non-IBD & Ref & Ref & Ref & Ref \\
\hline IBD & 3.11 & 1.60 & 5.90 & 0.002 \\
\hline \multicolumn{5}{|l|}{ Age, yr } \\
\hline $20-50$ & Ref & Ref & Ref & Ref \\
\hline$>50$ & 0.71 & 0.61 & 0.82 & $<0.001$ \\
\hline \multicolumn{5}{|l|}{ Race } \\
\hline Non-Hispanic White & Ref & Ref & Ref & Ref \\
\hline Non-Hispanic Black & 1.01 & 0.81 & 1.30 & 0.901 \\
\hline Others & 1.11 & 0.90 & 1.40 & 0.420 \\
\hline \multicolumn{5}{|l|}{ Education } \\
\hline$<$ High school & Ref & Ref & Ref & Ref \\
\hline High school & 0.91 & 0.63 & 1.21 & 0.301 \\
\hline Some college & 0.83 & 0.51 & 1.08 & 0.101 \\
\hline$\geq$ College & 0.72 & 0.52 & 0.91 & 0.021 \\
\hline \multicolumn{5}{|l|}{ Income poverty ratio, $\%$} \\
\hline$<100$ & Ref & Ref & Ref & Ref \\
\hline $100-299$ & 0.81 & 0.63 & 1.05 & 0.105 \\
\hline $300-499$ & 0.63 & 0.44 & 0.82 & 0.001 \\
\hline$\geq 500$ & 0.51 & 0.40 & 0.70 & $<0.001$ \\
\hline \multicolumn{5}{|l|}{ Overweight } \\
\hline Nonoverweight & Ref & Ref & Ref & Ref \\
\hline Overweight & 1.30 & 0.93 & 1.71 & 0.061 \\
\hline \multicolumn{5}{|l|}{ No. of comorbidities } \\
\hline 0 & Ref & Ref & Ref & Ref \\
\hline 1 & 1.22 & 0.94 & 1.51 & 0.090 \\
\hline 2 & 1.61 & 1.20 & 2.22 & 0.004 \\
\hline$\geq 3$ & 2.41 & 1.81 & 3.21 & $<0.001$ \\
\hline
\end{tabular}

OR, odds ratio; CI, confidence interval; IBD, inflammatory bowel disease; Ref, reference.

*All variables with $p$-values of $<0.2$ on univariate analysis (Table 1 ) were included in the final multivariate analysis.

pressive disorder in patients with IBD. This includes representative population studies completed in Canada based on structured diagnostic interview ${ }^{13}$ and several smaller studies looking at sample groups in England ${ }^{11}$ and the United States. ${ }^{14}$ The higher incidence of depression in IBD patients is thought to be multifactorial, including both physiologic and behavioral manifestations of the IBD process which put the patient at risk for comorbid stress and depression. ${ }^{15}$ One of the main physiologic drivers discussed in the literature is increased stress in patients with IBD. Increased perceived stress is shown to lead to higher instances of disease flare and exacerbation. ${ }^{7,16}$

Additionally, research has shown that IBD exacerbation or flare can lead to decreased psychological well-being ${ }^{17}$ which suggests a positive feedback loop effect between disease flare and depression. Several studies support this idea by showing that comorbid depression with IBD predicts a more negative disease course including more relapses, less response to treatment, ${ }^{14}$ and lower health related quality of life scores. ${ }^{18,19}$

Aside from more negative IBD outcomes, major depressive disorder by itself also puts patients at an increased risk for suicidal ideation and completed suicide. ${ }^{20}$ The present study found an increased risk of suicidal ideation in IBD patients with DS compared to non-IBD patients with DS. While this was not statistically significant, it does correlate with two previous studies which found an increased risk of suicide in patients with diagnosed CD. ${ }^{21,22}$ Recent research completed in a Danish population shows that this increased risk for completed suicide may also include patients with UC. ${ }^{23}$ Interestingly, our study shows that suicidal patients with IBD are much more likely to seek care from a mental health professional compared to suicidal patients in the general population. This might suggest that suicidal ideation in IBD patients is severe enough to seek help from a mental health 
Table 3. Comparison of the IBD Population with and without Depressive Symptoms

\begin{tabular}{|c|c|c|c|}
\hline \multirow[b]{2}{*}{ Covariate } & \multicolumn{2}{|c|}{ Subsets of IBD population } & \multirow[b]{2}{*}{ p-value } \\
\hline & $\begin{array}{l}\text { Depressive symptoms }(-) \\
\quad(\mathrm{n}=1,085,801)^{*}\end{array}$ & $\begin{array}{l}\text { Depressive symptoms (+) } \\
\quad(\mathrm{n}=1,022,930)^{*}\end{array}$ & \\
\hline Age, yr & & & 0.081 \\
\hline $20-50$ & 59 & 37 & \\
\hline$>50$ & 41 & 63 & \\
\hline Male sex & 56 & 30 & 0.062 \\
\hline Race & & & 0.911 \\
\hline Non-Hispanic White & 80 & 81 & \\
\hline Non-Hispanic Black & 7 & 5 & \\
\hline Others $^{\dagger}$ & 13 & 14 & \\
\hline Education & & & 0.612 \\
\hline$<$ High school & 20 & 28 & \\
\hline High school & 12 & 2 & \\
\hline Some college & 38 & 36 & \\
\hline$\geq$ College & 30 & 34 & \\
\hline Married & & & $<0.001$ \\
\hline Married/living with partner & 75 & 40 & \\
\hline Divorced/separated/widowed & 5 & 45 & \\
\hline Never married & 20 & 15 & \\
\hline Income poverty ratio, $\%$ & & & 0.623 \\
\hline$<100$ & 17 & 17 & \\
\hline 100-299 & 26 & 40 & \\
\hline $300-499$ & 9 & 13 & \\
\hline$\geq 500$ & 48 & 29 & \\
\hline Smoking $^{\ddagger}$ & 47 & 47 & 1.012 \\
\hline Overweight $^{\S}$ & 58 & 58 & 1.034 \\
\hline Anemia" & 1 & 11 & $<0.001$ \\
\hline C-reactive protein, $\mathrm{ng} / \mathrm{mL}$ & $0.45 \pm 0.15$ & $0.50 \pm 0.18$ & 0.711 \\
\hline IBD types & & & $<0.001$ \\
\hline Ulcerative colitis & 77 & 92 & \\
\hline Crohn's disease & 23 & 8 & \\
\hline No. of comorbidities ${ }^{\pi}$ & & & 0.414 \\
\hline 0 & 36 & 19 & \\
\hline 1 & 42 & 58 & \\
\hline 2 & 17 & 17 & \\
\hline$\geq 3$ & 5 & 6 & \\
\hline
\end{tabular}

Data are presented percent or mean \pm standard error.

IBD, inflammatory bowel disease.

*The data are presented as numbers weighted for a national estimate; ${ }^{\dagger}$ Others included Mexican American, other Hispanics and other races includ-

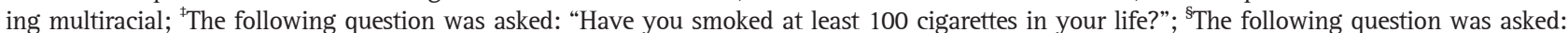
"Has a doctor or other health care professional ever told you that you were overweight?"; "The following question was asked: "During the past 3 months, have you been on treatment for anemia, sometimes called "tired blood" or "low blood"? (include diet, iron pills, iron shots, transfusions as treatment)"; "Comorbidities included hypertension, diabetes, coronary artery disease, stroke, congestive heart failure, liver disease, kidney disease, asthma, and cancer. All comorbidities were self-reported.

professional. In this regard, although our study does not have any direct data on actual suicidal attempts made, we assume that untreated suicidal patients with IBD are at an especially high risk for attempting and completing suicide. More research is required to further elucidate a link between completed suicide and depression in IBD patients. 
Table 4. Independent Factors Associated with Depressive Symptoms in an IBD Population

\begin{tabular}{|c|c|c|c|c|}
\hline Independent predictor* & OR & Lower limit of 95\% CI & Upper limit of 95\% CI & p-value \\
\hline \multicolumn{5}{|l|}{ Age, yr } \\
\hline $20-50$ & Ref & Ref & Ref & Ref \\
\hline$>50$ & 3.13 & 1.01 & 9.70 & 0.048 \\
\hline \multicolumn{5}{|l|}{ Sex } \\
\hline Female & Ref & Ref & Ref & Ref \\
\hline Male & 1.29 & 0.22 & 7.51 & 0.753 \\
\hline \multicolumn{5}{|l|}{ Marriage status } \\
\hline Married/living with partner & Ref & Ref & Ref & Ref \\
\hline Divorced/separated/widowed & 32.77 & 3.86 & 277.91 & 0.005 \\
\hline Never married & 2.01 & 0.20 & 20.70 & 0.515 \\
\hline \multicolumn{5}{|l|}{ Anemia } \\
\hline Anemia (absent) & Ref & Ref & Ref & Ref \\
\hline Anemia (present) & 4.10 & 0.30 & 65.40 & 0.277 \\
\hline \multicolumn{5}{|l|}{ IBD types } \\
\hline Ulcerative colitis & Ref & Ref & Ref & Ref \\
\hline Crohn's disease & 3.30 & 0.60 & 18.11 & 0.149 \\
\hline
\end{tabular}

IBD, inflammatory bowel disease; OR, odds ratio; CI, confidence interval; Ref, reference.

*All variables with p-values $<0.2$ upon univariate analysis (Table 3) were included in the final multivariate analysis.

Although this is an area of ongoing research, several studies suggest that treating depression in IBD patients can have a beneficial effect on both mood and disease course. A retrospective case review completed in $2012^{24}$ as well as a systematic review discussing antidepressant medications in $2006^{25}$ conclude that depression can be effectively treated in IBD patients. However, there is inconclusive evidence as to the direct effect of antidepressant pharmaceutical intervention on the IBD disease course itself (i.e., number of flares and exacerbations). While the direct effect of antidepressants on IBD disease flare is unknown, it has been shown that IBD patients with untreated comorbid psychiatric disorders are less compliant with IBD medication regimens which also leads to worse disease outcomes. ${ }^{8}$ In addition to pharmacologic intervention, there is considerable research as to the role for psychotherapy in IBD patients. While it is shown that certain patients with IBD benefit from psychotherapy, ${ }^{26}$ psychotherapy is not recommended for all patients diagnosed with IBD. This was confirmed by a 2011 Cochrane review. ${ }^{27}$

There is mounting evidence suggesting that appropriate treatment of the IBD process may reduce DS and improve health related quality of life scores. A 2015 study showed reduced depressive indices using Patient Health Questionnaire-9 (PHQ-9) scores for IBD patients receiving antitumor necrosis factor therapy. ${ }^{28}$ Similar findings were shown for IBD patients receiving azathioprine utilizing the health related quality of life and IBD questionnaire. $^{29}$

We have established that DS in IBD leads to worse outcomes, and there are possible treatments to decrease the instance of depression in IBD patients. Therefore, there is utility for screening for depression in IBD patients. This is reflected in the 2011 IBD treatment guidelines. ${ }^{4}$ There are several validated modalities for screening, including patient self-reporting utilizing the PHQ-9 form, or physician led questioning utilizing the Luebeck interview for psychosocial screening in patients with IBD. ${ }^{14}$ Screening can be done either by the gastroenterologist or the primary care physician. However, many IBD patients rely on their gastroenterologist for routine health maintenance. ${ }^{30}$ This suggests that gastroenterologists are in the best position for early identification and intervention of depression in at risk IBD patient populations. Early intervention includes direct prescription of medication, referral to the primary care doctor, or direct referral to a mental health professional.

With the data outlined in this study, special attention should be paid to elderly patients, and patients who are separated, divorced, or widowed. These two findings are supported by recent cohort studies completed looking into patients with IBD and comorbid depression. A 2014 study focusing on patients 65 years or older with IBD showed higher rates of depression in this population compared to younger age groups, which strengthens the findings in the present population based study. ${ }^{31}$ Additionally, a 2006 study investigated the coping strategies for depressed patients with IBD. This research reported that patients with IBD were more likely to be depressed if they had less interpersonal support. ${ }^{19}$ These findings coincide with the present study that divorced/separated/widowed patients are at an increased risk for depression in the setting of IBD.

Little research currently exists as to the overall percentage of IBD patients routinely screened for depression, whether it 
be from a gastroenterologist or primary care physician. The data presented in this study show that approximately 36\% of patients with IBD and DS visited a mental health professional for the depression. While this is higher than the general population, it shows that the majority of depressed patients with IBD are not receiving formal mental health care. However, this data does not provide an understanding of the percentage of patients screened for depression and/or treated for depression directly from their gastroenterologist. Future studies should investigate the adequacy of screening for depression in IBD patients, emphasizing the importance of screening in elderly and separated/ divorced/or widowed patients. Further research is also needed to examine the treatment approach for positively screened patients whether it be from the gastroenterologist directly, the primary care physician, or a mental health professional.

Our study has some limitations. First, the study was based on self-reported history of IBD and DS, which can be subject to recall bias. Second, we were not able to evaluate the correlation between disease activity and the level of DS because the survey did not include question on disease activity (flare vs clinical remission). But inclusion of C-reactive protein might have alleviated this limitation to some degree. Third, our study is also limited by noninclusion of other IBD-related surgeries or admissions or pathological diagnosis of IBD like structuring vs. penetrating disease, which might signify severity of the disease and might also be associated with DS. Lastly, our study was based on the DS of the respondents rather than a validated depression questionnaire. Despite these limitations, our study provides a broader prospective on psychological impact of IBD on U.S. population.

In conclusion, our study shows IBD is an independent risk factor of DS in U.S. population. Elderly and separated/divorced/ or widowed individuals with IBD are especially vulnerable to DS. We recommend IBD patients should be routinely screened for depression and appropriate psychological support should be provided to them when screened positive. Future studies should focus on further risk-stratification, screening modality and management of depression in IBD population.

\section{CONFLICTS OF INTEREST}

No potential conflict of interest relevant to this article was reported.

\section{REFERENCES}

1. Loftus EV Jr. Clinical epidemiology of inflammatory bowel disease: incidence, prevalence, and environmental influences. Gastroenterology 2004;126:1504-1517.

2. Kappelman MD, Rifas-Shiman SL, Kleinman K, et al. The prevalence and geographic distribution of Crohn's disease and ulcerative colitis in the United States. Clin Gastroenterol Hepatol
2007;5:1424-1429.

3. Ganz ML, Sugarman R, Wang R, Hansen BB, Håkan-Bloch J. The economic and health-related impact of Crohn's disease in the United States: evidence from a nationally representative survey. Inflamm Bowel Dis 2016;22:1032-1041.

4. Mowat C, Cole A, Windsor A, et al. Guidelines for the management of inflammatory bowel disease in adults. Gut 2011;60:571-607.

5. Mittermaier C, Dejaco C, Waldhoer T, et al. Impact of depressive mood on relapse in patients with inflammatory bowel disease: a prospective 18-month follow-up study. Psychosom Med 2004;66:79-84.

6. Mawdsley JE, Rampton DS. Psychological stress in IBD: new insights into pathogenic and therapeutic implications. Gut 2005;54:1481-1491.

7. Bernstein CN, Singh S, Graff LA, Walker JR, Miller N, Cheang M. A prospective population-based study of triggers of symptomatic flares in IBD. Am J Gastroenterol 2010;105:1994-2002.

8. Nigro G, Angelini G, Grosso SB, Caula G, Sategna-Guidetti C. Psychiatric predictors of noncompliance in inflammatory bowel disease: psychiatry and compliance. J Clin Gastroenterol 2001;32:6668.

9. Persoons P, Vermeire S, Demyttenaere K, et al. The impact of major depressive disorder on the short- and long-term outcome of Crohn's disease treatment with infliximab. Aliment Pharmacol Ther 2005;22:101-110.

10. Fuller-Thomson E, Sulman J. Depression and inflammatory bowel disease: findings from two nationally representative Canadian surveys. Inflamm Bowel Dis 2006;12:697-707.

11. Kurina LM, Goldacre MJ, Yeates D, Gill LE. Depression and anxiety in people with inflammatory bowel disease. J Epidemiol Community Health 2001;55:716-720.

12. Centers for Disease Control and Prevention (CDC). The National Health and Nutrition Examination Survey [Internet]. Atlanta: CDC; 2014 [cited 2015 Nov 6]. Available from http://www.cdc.gov/ nchs/nhanes/about_nhanes.htm.

13. Walker JR, Ediger JP, Graff LA, et al. The Manitoba IBD cohort study: a population-based study of the prevalence of lifetime and 12-month anxiety and mood disorders. Am J Gastroenterol 2008;103:1989-1997.

14. Graff LA, Walker JR, Bernstein CN. Depression and anxiety in inflammatory bowel disease: a review of comorbidity and management. Inflamm Bowel Dis 2009;15:1105-1118.

15. Sajadinejad MS, Asgari K, Molavi H, Kalantari M, Adibi P. Psychological issues in inflammatory bowel disease: an overview. Gastroenterol Res Pract 2012;2012:106502.

16. Levenstein S, Prantera C, Varvo V, et al. Stress and exacerbation in ulcerative colitis: a prospective study of patients enrolled in remission. Am J Gastroenterol 2000;95:1213-1220.

17. Simrén M, Axelsson J, Gillberg R, Abrahamsson H, Svedlund J, Björnsson ES. Quality of life in inflammatory bowel disease in remission: the impact of IBS-like symptoms and associated psychological factors. Am J Gastroenterol 2002;97:389-396. 
18. Guthrie E, Jackson J, Shaffer J, Thompson D, Tomenson B, Creed F. Psychological disorder and severity of inflammatory bowel disease predict health-related quality of life in ulcerative colitis and Crohn's disease. Am J Gastroenterol 2002;97:1994-1999.

19. Jones MP, Wessinger S, Crowell MD. Coping strategies and interpersonal support in patients with irritable bowel syndrome and inflammatory bowel disease. Clin Gastroenterol Hepatol 2006;4:474481.

20. Kessler RC, Borges G, Walters EE. Prevalence of and risk factors for lifetime suicide attempts in the National Comorbidity Survey. Arch Gen Psychiatry 1999;56:617-626.

21. Persson PG, Bernell 0, Leijonmarck CE, Farahmand BY, Hellers G, Ahlbom A. Survival and cause-specific mortality in inflammatory bowel disease: a population-based cohort study. Gastroenterology 1996;110:1339-1345.

22. Prior P, Gyde S, Cooke WT, Waterhouse JA, Allan RN. Mortality in Crohn's disease. Gastroenterology 1981;80:307-312.

23. Gradus JL, Qin P, Lincoln AK, et al. Inflammatory bowel disease and completed suicide in Danish adults. Inflamm Bowel Dis 2010;16:2158-2161.

24. Goodhand JR, Greig FI, Koodun Y, et al. Do antidepressants influence the disease course in inflammatory bowel disease? A retrospective case-matched observational study. Inflamm Bowel Dis
2012;18:1232-1239.

25. Mikocka-Walus AA, Turnbull DA, Moulding NT, Wilson IG, Andrews JM, Holtmann GJ. Antidepressants and inflammatory bowel disease: a systematic review. Clin Pract Epidemiol Ment Health 2006;2:24.

26. McCombie AM, Mulder RT, Gearry RB. Psychotherapy for inflammatory bowel disease: a review and update. J Crohns Colitis 2013;7:935-949.

27. Timmer A, Preiss JC, Motschall E, Rücker G, Jantschek G, Moser G. Psychological interventions for treatment of inflammatory bowel disease. Cochrane Database Syst Rev 2011;(2):CD006913.

28. Horst S, Chao A, Rosen M, et al. Treatment with immunosuppressive therapy may improve depressive symptoms in patients with inflammatory bowel disease. Dig Dis Sci 2015;60:465-470.

29. Bastida G, Nos P, Aguas M, et al. The effects of thiopurine therapy on health-related quality of life in inflammatory bowel disease patients. BMC Gastroenterol 2010;10:26.

30. Moscandrew M, Mahadevan U, Kane S. General health maintenance in IBD. Inflamm Bowel Dis 2009;15:1399-1409.

31. Long MD, Kappelman MD, Martin CF, Chen W, Anton K, Sandler RS. Risk factors for depression in the elderly inflammatory bowel disease population. J Crohns Colitis 2014;8:113-119. 